\title{
Comunicación visual y violencia epistémica en México
}

\begin{abstract}
Verónica Vázquez-Valdés ${ }^{1}$
RESUMEN: El texto presenta un análisi reflexivo sobre la cultura visual de los pueblos indígenas de la Sierra Madre Occidental en México. En el desarrollo del trabajo, se resumen los resultados del análisis de la cultura visual de los indígenas totonaco, a partir de fotografías tomadas por ellos mismos. Se describe la ruptura epistémica entre la concepción del uso de la fotografía occidental y la relevancia que la misma tecnología tiene para los indígenas. Lo anterior hace evidente el desconocimiento que los gobiernos tienen al hacer las campañas visuales de comunicación social y el impacto del que estas carecen.
\end{abstract}

Palabras clave: fotografía, cultura visual, totonacos, indígenas, México.

\section{Comunicação visual e violência epistêmica no México}

RESUMO: O texto apresenta uma análise reflexiva sobre a cultura visual dos povos indígenas da Serra Madre Ocidental no México. No desenvolvimento do trabalho, os resultados da análise da cultura visual dos nativos totonicos são resumidos, a partir de fotografias tiradas por eles. A ruptura epistêmica entre a concepção do uso da fotografia da cultura dominante e a relevância que a mesma tecnologia tem para os nativos é apresentada. O que precede torna evidente a ignorância que os governos têm ao fazer campanhas de comunicação visual e o impacto que isso possui nas comunidades.

Palavras-chave: fotografia, cultura visual, totonacos, indígenas, México.

\section{Visual communication and epistemic violence in Mexico}

ABSTRACT: The text presents a reflexive analysis on the visual culture of the indigenous peoples of the Sierra Madre Occidental in Mexico. In the development of the work, the results of the analysis of the visual culture of the Totonac natives are summarized, from photographs taken by them. The epistemic rupture between the conception of the use of photography off the dominant culture and the relevance that the same technology has for indigenous people is described. The foregoing makes evident the ignorance that governments have when making visual communication campaigns and the impact they lack.

Key words: photography, visual culture, totonacs, indigenous, Mexico.

\section{INTRODUCCIÓN}

México se ha caracterizado por su diversidad biológica y étnica entre todas las naciones del mundo, sin embargo es la diversidad cultural, reflejada en sus étnias, la que más destaca en el devenir de los tiempos.
Navarrete (2008) señala que México es un país cultural y étnicamente plural, como lo ha sido desde hace miles de años. Esta pluralidad es una realidad viviente y dinámica que se ha adaptado a todos los cambios experimentados en nuestro país.

Mondragón (2010) enfatiza que:

\footnotetext{
${ }^{1}$ Profesora Investigadora de la Benemérita Universidad Autónoma de Puebla, México.
} 
Existe una estrecha relación lingüística entre la lengua y la cultura, es decir, entre la forma en que se estructuran el habla cotidiana, la cosmovisión y las costumbres. En ese sentido, el mantenimiento del uso cotidiano y persistente de las lenguas originales de los pueblos indígenas de México, como una estrategia de sobrevivencia cultural -y física- de larga duración, ha sido uno de los principales obstáculos para la implantación de los proyectos encaminados a integrar culturalmente a las comunidades indígenas en la "sociedad nacional", y a impulsar tanto en la Colonia, como en el México independiente, posrevolucionario y contemporáneo. ( $p$. 221)

Con el paso del tiempo han existido diversas maneras para describir esta diversidad cultural desde la postura geopolítica territorial, espacial, estatal, sobre cómo analizar, describir e informar dicha diversidad en México a partir de diversas instituciones como el Instituto Nacional Indigenista (INI), Comisión Nacional para el Desarrollo de los pueblos indígenas (CDI), Instituto Nacional de Antropología e Historia (INAH), Instituto Nacional de Lenguas Indígenas (INALI), por mencionar algunas.

De acuerdo con el Censo de Población 2010, en México hay unos 16 millones de indígenas; de ellos, cerca de 7 millones hablan español y alguna de las lenguas nacionales, mientras que un millón son monolingües. En en el Catálogo de Lenguas Indígenas Nacionales del Instituto Nacional de Lenguas Indígenas (2008) se menciona que en México se hablan 68 lenguas que tienen 364 variantes lingüísticas pertenecientes a 11 familias.

En este texto, hablaré de los Totonacos de la Sierra Norte de Puebla.

\section{2 ¿QUIÉNES SON LOS TOTONACO?}

Los totonaco son un grupo étnico mexicano de origen prehispánico. Hoy día habitan una porción que incluye parte de los estados de Puebla y Veracruz. Su territorio era más extenso a la llegada de los europeos, que en el tiempo actual; sin embargo aún sigue siendo considerable.

Entre montañas verdes con frutos tropicales, ríos con abundante agua y animales extraños al ojo citadino, se encuentra el Totonacapan, que no es sino la región que han habitado los miembros del pueblo totonaco desde tiempos inmemoriales. Sus límites han sido modificados y sus poblaciones han sido testigos de grandes acontecimientos sociales y han protagonizado algunas escenas de la historia nacional (DEANCE y VÁZQUEZ, 2010, p. 40).

Ruiz (1991) señala que la Sierra Norte de Puebla (SNP) desde el punto de vista cultural, conforma una región interétnica en la que conviven cinco grupos étnicos: mestizo, nahua, totonaco, tepehua y otomí. Por lo general, las comunidades están compuestas por hablantes de un solo grupo étnico, aunque pueden pertenecer a un mismo municipio grupos hablantes de distinta lengua indígena; en algunas comunidades que son puntos importantes de convergencia conviven mestizos e indígenas o indígenas de diferente filiación étnica, lo que hace que en algunos lugares existan personas trilingües.

El municipio de Tlacuilotepec es uno de los 68 municipios pertenecientes a la SNP; cuenta con 17764 habitantes, según el XII Censo General de Población y Vivienda 2000. Una de las comunidades que le conciernen es San Pedro Petlacotla, el cual está asentado en la ladera oeste de un cerro, se puede delimitar esta comunidad con cinco 
accidentes geográficos que lo rodean con relativa cercanía: al noroeste la barranca San Pedro, al suroeste la barranca los arroyos, al este el cerro san Pedro, al sureste el arroyo el Caliche y al noreste la barranca dos arroyos.

En este municipio existen 33 localidades y siete juntas auxiliares. Como junta auxiliar, San Pedro tiene registro civil y cárcel y la cabecera municipal se encuentra a cuatro horas promedio por el camino de terracería rumbo al norte, además posee dos preescolares, uno rural y otro federal-indígena, dos escuelas primarias, una federal y otra bilingüe, una tele secundaria y un bachillerato federal. Referente a la tenencia de la tierra, hay propiedad privada y una amplia sección de tierra ejidal a la cual llaman "el barrio".

La mayoría de las actividades que hacen día con día los totonaco son: desayunar café con pan y al medio día almuerzan algún guisado con chile y tortilla; los hombres van a sus cosechas a trabajar y traen fruta y verdura para la comida. A veces la mujer los acompaña para ayudarlos principalmente a la recolección de café y lima; los niños van a la escuela y las mujeres se quedan en casa a cuidar a los hijos pequeños y hacen las labores domésticas, entre ellas limpiar la casa, poner el nixtamal, hacer comida y darle de comer a sus animales. Los totonaco comen de cuatro a seis de la tarde. Suelen bañarse en la tarde en temazcal o simplemente con agua fría, pero hay algunas personas que calientan su agua en leña. Y en la noche ven televisión. Los sábados y domingos puede ir al campo a trabajar la familia entera, las mujeres preparan alimentos para el medio día. Si no se va a trabajar, se visitan parientes y compadres o se descansa en casa. Algunas veces, los varones van a pescar al río o se juntan para ir de cacería, los jóvenes juegan pelota o van a pasear.

\section{UN ACERCAMIENTO ÉTICO A LOS TOTO- NACO}

La siguiente anécdota fue el impulso que me llevó a realizar este trabajo. Era el mes de julio, mi colega Iván y yo fuimos padrinos de un niño totonaco quien finalizaba su sexto año de primaria, en el municipio de Zozocolco de Hidalgo, Veracruz. Acudimos a esa región para ese compromiso y también para realizar trabajo de campo. Además de mi cámara de $35 \mathrm{~mm}$ llevaba una cámara instantánea "polaroid" para dejar algunas fotos inmediatamente, ya que nos sería muy difícil regresar a ese lugar.

En la entrega de diplomas de la salida de sexto año en la escuela rural indígena de la región, una señora me pidió que le tomara una foto a su hija con su madrina. A mí se me hizo fácil tomar la foto en el momento en que recibía su certificado en manos del presidente municipal. Al entregarla a la señora, no la vi muy contenta con la foto, su reacción fue muy seria y seca. Sin embargo, la madrina me había pedido una foto con la ahijada sosteniendo el regalo que le traía a la niña. Esta foto fue disputada por la mamá y la madrina dejando, la de la entrega de papeles, en el olvido.

Posteriormente me percaté que las personas que traían cámara no tomaban fotos en la entrega de papeles sino tiempo después donde los padrinos posarían desahogadamente con los ahijados dejando de lado a las autoridades o personalidades del evento. Es curioso ver como, orientada por mi formación occidental, me pareció lo más correcto registrar la entrega de un documento "valioso" dado por una autoridad; sin embargo para los totonaco, no es así, lo 
importante es tener el recuerdo de la madrina con la hija pasando el certificado escolar y las autoridades a un segundo plano. En una frase, lo importante para los totonaco es conservar el recuerdo del compadre o la comadre con los ahijados, dándole mayor importancia a las relaciones de compadrazgo que a las autoridades o las formas de legitimación.

Esta experiencia fue un choque cultural tremendo, pues yo me creía una fotógrafa infalible por los elogios recibidos en mis trabajos urbanos y de repente era despreciada por una mujer que simplemente pertenecía a otra cultura, es decir a otra realidad. Fue esa situación tan traumante la que me motivó a hacer esta investigación. Es así como surgió la idea de darles la cámara fotográfica a personas de una comunidad para que ellos mismos registren su cultura y su vida desde su visión y la manera propia de percibir el mundo, privilegiando los momentos que a su parecer son de mayor importancia, debido a que lo que es importante para mí o para quienes estamos formados en una cultura hegemónica, no es necesariamente importante para ellos.

Después de un año de involucrarme en la cotidianidad de la comunidad y de participar en la vida de las personas, decidí presentar mi proyecto de investigación al presidente de la Junta Auxiliar de San Pedro Petlacotla y con conocimiento de mis intenciones por parte del gobierno municipal de Tlacuilotepec, estuvo de acuerdo en apoyarlo.

Debido a que la población indígena en general ha sido objeto de intrusión constante por parte de diversos proyectos sociales, mi objetivo era no causar incomodidad ni discordia en la comunidad, por lo que evité hacer la entrega de cámaras de manera ma- siva, llevando sólo dos cámaras pocket automáticas muy sencillas de manejar e intercambiándolas entre mis colaboradores al término de uso de alguno de ellos. Esto también me permitió dar un seguimiento personalizado del fotógrafo y los problemas que fueran surgiendo en el avance de las tomas fotográficas.

Mi muestra fue de 16 personas totonacos de diversas edades: 4 adultos, 4 infantes, 4 adolescentes y 4 jóvenes. De cada generación se les dio la cámara a 2 personas masculinas y 2 personas femeninas.

La primera entrega de cámaras fue al presidente auxiliar, Juan Flores, y a Juana Soto, partera y curandera de la comunidad. Les enseñé las pocas funciones de la cámara fotográfica: cómo encenderla, cómo apagarla, cómo utilizar la función de flash y del disparador. Les pedí que siempre utilizaran la función de flash encendido, pues me di cuenta que el interior de las casas es muy obscuro y no saldría la imagen fotográfica y por otro lado, en lugares exteriores, el flash serviría como luz de relleno.

La única indicación que les hice a cada uno de mis colaboradores de manera idéntica: "Al tomar una foto, abre la cámara (tapa del obturador) enciende el flash y en cuanto <esté el foquito en verde>, aprietas el botón (botón disparador). Te aviso que lo que veas por la ventanita (ventana del visor) es lo que saldrá en tu foto, tal cual y como lo veas."

Les pedí que tomaran fotografías de lo que ellos quisieran. Por lo regular les dejaba la cámara de dos a tres semanas, después se las recogía y tiempo después traía las fotos en un álbum fotográfico, con la finalidad de que me comentaran algo de ellas.

Es necesario mencionar que a las 16 personas que les ofrecí la cámara fotográfica 
las fui conociendo durante el primer año de trabajo de campo: fui a sus milpas, cociné en sus fogones, compartimos los alimentos, bordé con ellas y fui al río con ellos, me platicaron sus vidas y les compartí la mía, dormí en la casa de muchos de ellos e inclusive hasta algunos de ellos comieron en mi mesa y durmieron en mi casa. Por lo anterior, fue fácil que aceptaran ayudarme a mi proyecto de investigación, creo que sin la convivencia y la sensibilidad de todos, no hubiera sido posible realizar este trabajo.

\section{ANÁLISIS DE LA CULTURA VISUAL DE LOS TOTONACO.}

Después de analizar 456 fotografías de los 16 fotógrafos del grupo étnico totonaco mediante el modelo tetradimensional para el análisis de imágenes fotográficas, llegué a las siguientes reflexiones:

a) Los totonaco con experiencia migratoria, reflejaron mayor diversidad en la elección de planos, ángulos y eje al tomar sus fotos, debido al contacto constante de una cultura visual más diversificada, presente en las ciudades y en las comunicaciones de cobertura nacional e internacional como pueden ser: prensa, anuncios espectaculares, revistas, medios electrónicos, etcétera. Entonces podemos decir que la reproducción de las imágenes fotográficas están altamente correlacionadas con las experiencias visuales previas.

b) Los totonaco están acostumbrados a percibir las imágenes visuales de izquierda a derecha y no de arriba a bajo o de forma vertical. Debido a que el promedio de fotografías tomadas en eje horizontal fue de $78.3 \%$. Posiblemente, este promedio también se deba a la comodidad por a- garrar la cámara fotográfica en forma horizontal.

c) La teoría de los puntos áureos, se puede aplicar a diversas culturas que no necesariamente tengan el referente occidental, ya que el $90.6 \%$ de las tomas realizadas por los totonaco encuadraron sus actantes en la sección áurea.

d) En la cultura totonaco, no existe tanto contacto físico o acercamiento entre las personas, en comparación con otras culturas y esto se refleja en las fotografías tomadas en plano general por los totonaco con un $86.4 \%$.

e) Para los totonaco es mejor realizar sus actividades laborales y de esparcimiento en el día, a la luz del Sol. Tal vez se deba a que en la cultura totonaco el Sol, Chichiní, es el gran dios totonaco, el Creador y el Dueño del Maíz. Tiene a sus órdenes, directamente o por medio de Aktsini, dios del Agua, a los Truenos y a los Vientos, según Ichon (1990). El promedio de las fotografías realizadas en el día fue $71.4 \%$ y en la noche el $28.6 \%$.

Con base en lo anterior, invito a aquellos realizadores que trabajen en el diseño materiales de difusión visual en regiones campesinas que, al hacer algún trabajo en zonas rurales especialmente indígenas, tomen en consideración investigaciones como la aquí se sintetiza para lograr mayor eficiencia en los trabajos de comunicación visual.

Si en las pintas de bardas o en las mantas de difusión de programas como los de salud o derechos humanos, se presentaran los actantes completos en lugar de los close up que se hacen de los niños enfermos y las madres golpeadas, probablemente causarían mayor impacto en estas regiones. Por el contrario, en nuestra cultura, para invitarnos a colaborar con UNICEF o Cruz Roja, son 
necesarias las tomas cercanas y a detalle que nos causan mayor impacto.

Si bien este trabajo no basta para hacer un manual de percepción visual entre las culturas amerindias, es un buen referente para saber que los parámetros de la cultura visual, la estética y la mercadotecnia occidental no son necesariamente extensivos a todas las culturas; en otras palabras quiero dar cuenta que los acercamientos de rostro y la angulación contrapicada, por mencionar algún ejemplo, que son tan significativos e impactantes para nosotros, no lo son necesariamente para ellos.

Finalmente, se puede decir que la fotografía para los totonaco es un elemento de estatus, ya que no todos tienen acceso a ella. Quien registra un evento mediante la fotografía, tiene el poder y la legitimidad de ese recuerdo. Además, en la cultura de los totonaco se valora más la presencia entera físicamente de los actantes y no tanto la composición estética occidental de la fotografía, como son los primeros planos.

Por lo que, considero que este trabajo contribuye a la difusión visual en zonas rurales, especialmente indígenas, para lograr mayor eficiencia en los trabajos de comunicación visual. Así que cuando vayamos a realizar un trabajo visual para las culturas amerindias debemos cuestionarnos primero cómo es la percepción visual entre esas culturas para poder llevar a cabo cualquier propaganda, publicidad, campaña, etc. a un buen fin.

\section{REFERENCIAS}

DEANCE, Iván \& VÁZQUEZ VALDÉS, Verónica (2010). "La lengua originaria ante el modelo intercultural en la universidad intercultural del estado de Puebla" en Cuicuilco, Revista de la Escuela Nacional de Antropología e Historia. 17(48). 35-47.

NAVARRETE, F. (2008). Los pueblos indígenas de México. México: CDI.

MONDRAGÓN, J. (2010). El uso de la lengua indígena y la educación. Del integracionismo estatal a las alternativas indígenas. En Los pueblos indígenas de Puebla. Atlas Etnográfico. (pp. 217-260). México: Gobierno del Estado de Puebla / Instituto Nacional de Antropología e Historia.

(10 de agosto de 2015). Puebla, cuarto estado con mayor población indígena en México. e-econsulta. Recuperado de http:// www.e-consulta.com.mx/nota/2015-0810/sociedad/puebla-cuarto-estado-conmayor-poblacion-indigena-en-mexico.

(31 de marzo de 2015). Las 364 variantes de las lenguas indígenas nacionales, con ALGÚN riesgo de desaparecer: INALI. Recuperado de http://www.inali.gob.mx/en/comu nicados/451-las-364-variantes-de-las-lengu as-indigenas-nacionales-con-algun-riesgode-desaparecer-inali.html) RUIZ LOMBARDO, Andrés. Cafeticultura y economía totonaca. México. INICONACULTA, 1991. 